\title{
Program Principles for the Arrangement of Traffic Areas in Romani Settlements
}

\author{
Milena GRBIĆ*, Igor JOKANOVIĆ, Viktorija ALADŽIČ, Olivera DULIĆ
}

\begin{abstract}
Approach to solving key issues of Romani settlements in the region still does not have real designers' answers. It is the unknowns about the Romani lifestyle that cause lack of methods and techniques for selection and development of design and improvement of these settlements. In order to overcome the deficit of professional knowledge, the intention of the paper is to show that only after recognizing and establishing the relationship between the spatial and social level in settlements, it is possible to determine, explain and systematize the basic principles for adequate formation and functioning of the settlement's traffic network. Undoubtedly, the manner of use and consequently the principles are not characteristic for the usual interpretation of the street by the majority of non-Romani population. In this paper, the relativization of standard features is recognized as one of the key places in creating design principles that provide an adequate environment for the Romani community in the concept of modern society as culturally plural, and positioning traffic design as an important factor in this process.
\end{abstract}

Keywords: relativization of traffic infrastructure design; Romani settlements; Romanipen; traffic areas

\section{INTRODUCTION}

The quality of living conditions in Romani settlements varies from country to country, but it is possible to draw a general conclusion that they are lower than the conditions in which the majority non-Romani population lives. The Parliamentary Assembly of the Council of Europe, by Recommendation 1203 of 1993 [1], calling the Romani a 'true European minority', determined the European Union to create a social space through legal and institutional measures that the Romani would recognize as their homeland. By analysing a number of situations, Romani are characterized as a highly deprived ethnic community, with a specific lifestyle that prevents them from exercising their rights, or, when exercising their rights, pushes them into a kind of silent assimilation with the majority population and its lifestyle through adjustment to rigid institutional and administrative frameworks [2]. In order to overcome this situation, international, governmental and non-governmental organizations have gradually defined a number of documents that indicate the necessity that all projects related to Romani and Romani settlements must not imply a renunciation of ethno-cultural identity.

At the moment, numerous fields overlap the Romani settlement as an object of theoretical speculation, which, by means of books, articles, expert reports and documents, deal with the issue primarily from a legal, sociological and economic point of view. Only a small number of papers observe this topic from a design perspective, from the position of urban planning, architecture and civil engineering. The recommendations of independent researchers and organizations [3, 4] related to Romani settlements are slowly being developed and awaiting implementation, so there is no feedback in the form of good practice. Pioneering endeavours in mapping and analysing existing Roma settlements, done by Vuskanović-Macura [5], represent a valuable starting point and significantly facilitate the beginnings of field research. The methodology of field research itself depends on creativity and sublimation of previous knowledge about the subject of research. Moreover, the major topic of most of the recent researches is the housing aspect and providing opportunities to meet basic needs such as health, education, employment, etc.
Previous research by the author [6], conducted in numerous Roma settlements, was primarily focused on the impact of the cultural framework and lifestyle of the Roma community on the existing level of organization of land use, as well as opportunities to improve the spatial organization of settlements and housing. It has been shown that within Romani settlements, several inter-conditioned basic features of the functional organization of the community represent the ethos of forming the character of spatial structures. This was an important starting point for the research that will be presented in this paper, because it clearly indicated the fact that Roma culture must have a certain influence, actually a consequence for street communications. Romani culture is diverse and difficult to universalize, but there are attributes on which that universality rests. As Ozaki explained, culture here means a relatively organized system of shared meanings [7]. They are defined by Romanipen, i.e. Romani cultural framework, and consists of a strong identification of the individual and the community, loyalty to the family and the community, which together manifest themselves in a collective way of life. The collective way of life has, as proven, played a crucial role in the way of grouping houses and auxiliary facilities, their orientation towards open or private space, the formation of characteristic spatial divisions into public, common and private, built and unbuilt, as well as the way and type of formation and open space treatment [6].

Given that Romani settlements had not been approached from the point of view of recognizing and establishing the relationship between the spatial and social level, the aim of this paper is to show that in the case of other spatial sub-systems, such as communications, i.e. traffic areas, only from context of the collective way of life, it is possible to determine, explain and systematize the basic principles in their formation and functioning. Undoubtedly, those principles are not specific for the usual interpretation and acceptance of the street by the majority non-Romani population.

The research that shows and confirms this intention will be presented in the second part of the paper, and was performed on reference types of existing Romani settlements. Romani settlements, divided according to the characters of physical structure into types (slum and 
unsanitary settlement), were identified in urban areas in Serbia (Belgrade, Niš, Subotica), Montenegro (Podgorica, Berane), Bosnia and Herzegovina (Banja Luka, Sarajevo, Tuzla, Bijeljina) and Northern Macedonia (Skopje, Ohrid, Strumica, Kočani).

In the methodological sense, the research, presented and discussed in the paper, with a previous analysis of the material from primary and secondary sources, included field observations and recording of street use, as well as conversations with residents to clarify and deepen the knowledge gained.

Further development of the paper, the third part, refers to the comparative analysis of research results with a preliminary framework of possibilities prescribed by existing and valid documents and/or rules of road network design, in order to express and classify the described facts about streets in Romani settlements, as usable base of program principles for design.

Creating a database of explained and documented facts about streets in Romani settlements has been recognized as an important contribution to the formation of project material that would have its application in various problem-solving strategies in Romani settlements. This procedure enables a more successful interpretation of generally applicable regulations for the design of traffic infrastructure and associated/complementary open public spaces in the implementation of socially responsible design concepts, which is also the main contribution of the paper.

\section{STREETS IN ROMANI SETTLEMENTS - RESEARCH OF THE CURRENT SITUATION}

The term settlement, most generally, indicates a phenomenon that contains three defining elements: name, territory and population. The term 'Romani' explains the population inhabiting it in more detail, as these settlements are inhabited mostly by the Romani [8]. We were specifically interested in settlements that are considered non-legal according to the institutional status. The curiosity of non-legal Romani settlements lies in the fact that they were created by the Romani themselves within unbuilt parts of the cities, without the professional influence, only according to the functioning of their everyday life. In that sense, the potential to enhance knowledge about Romani living refers to the possibility that spatial structure of the settlement also integrates elementary traits of family life, lifestyle, cultural behaviour patterns and other values concerning the Romani everyday life [9]. We analysed old non-legal Romani settlements where the Romani have lived for several decades so that we could analyse changes in structures and organization. Field observation technique of daily activities was applied in duration of 3 days per settlement. During that time, space utilization with an emphasis on the streets (i.e. communications) was observed and noted accordingly, the summary of collected data being presented in the following paragraphs. All conclusions were checked and supplemented in conversations with residents.

According to the differences in the characters of the physical structure, the observed Romani settlements can be divided into slums and unsanitary settlements.

Slums were created as improvised, temporary shelters that eventually became permanent settlements. According to the institutional status, these settlements were created mostly spontaneously, on undeveloped terrain for which there was no planning documentation at the time of the settlement creation. In slums people live in barracks built with waste material (old wooden boards, doors, waste nylon, waste sheet metal or cardboard). Inhabitants of slums are very poor and are mainly engaged in collecting secondary raw materials. The field research included following settlements: Belgrade (Serbia) Grmeč; Niš (Serbia) Crvena Zvezda; Skopje (North Macedonia) Topana; Sarajevo (Bosnia and Herzegovina) Mošćanica (Fig. 1).

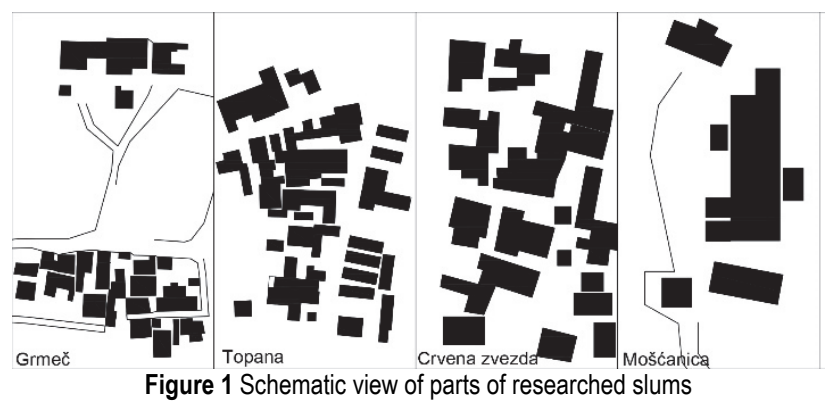

Unsanitary settlements were created spontaneously by building permanent houses as a type of housing on undeveloped land for which there was no planning documentation at the time of its creation. Permanent houses are built of standard construction materials, by the usual construction methods. The population of unsanitary settlements is of better economic status than the population of slums. They are engaged in collecting secondary raw materials in a smaller percentage than in slums, lowincome occupations, while a certain number of inhabitants are often on temporary work abroad. Settlements covered through the field research were: Belgrade (Serbia) Rupe; Subotica (Serbia) Haladaš; Berane (Montenegro) Talum; Podgorica (Montenegro) Konik; Sarajevo (Bosnia and Herzegovina) Crni vrh Gorica (Fig. 2).

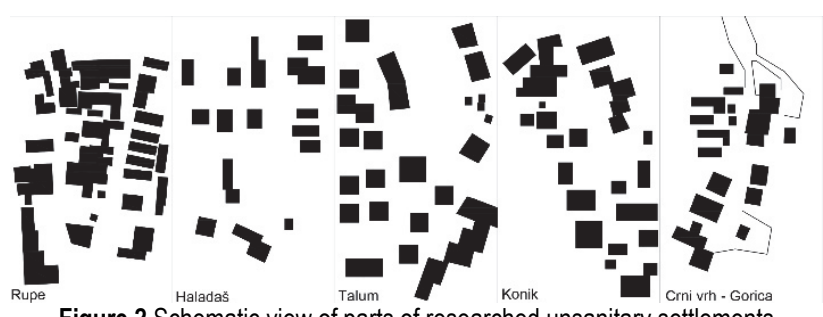

Figure 2 Schematic view of parts of researched unsanitary settlements

In the social sense, all the observed settlements function in a similar way. When referring to the analysis of primary use of space, which was determined by observation, it is noticeable that the collective lifestyle of the community in a fine nuance of preferences differentiates this social relationship into: family neighbourhood, closer neighbourhood and community of settlements, which as such reflect on the physical and functional dimension of streets. Family neighbourhood represents the spatial and kinship closeness and dependence of members in the form of sharing daily responsibilities. It is formed within a courtyard group of buildings, i.e. one lot where the members of the closest family live, 6 to 10 of them in two to three residential 
buildings. Such a close neighbourhood is positioned within several lots and is affected by physical proximity. The community of settlements represents the entire population of one Romani settlement.

The analysis of complex spatial organizations of communications and streets in the observed settlements according to the mentioned types, as places of synthesis of spatial and social dimensions, distinguished characteristic forms of behaviour and characteristic street structure (which should be transferred to future design of settlements for Romani population). This analysis is summarized in the continuation of the paper with the presentation of the basic shapes and elements of the streets, and graphic illustrations.

In the slums, the streets' surface is not treated with solid materials, but their existence and physiognomy are recognized by the trampled earth trace, created by use (Fig. $3)$. The street, in addition to the necessary communication through the settlement and access to the courtyards, also represents a gathering place. In conjunction with the courtyards of courtyard groups of buildings, it participates in the formation of the undeveloped space as a gathering place of the closer neighbourhood of the settlement.



Figure 3 Drawing of the street physiognomy in a slum

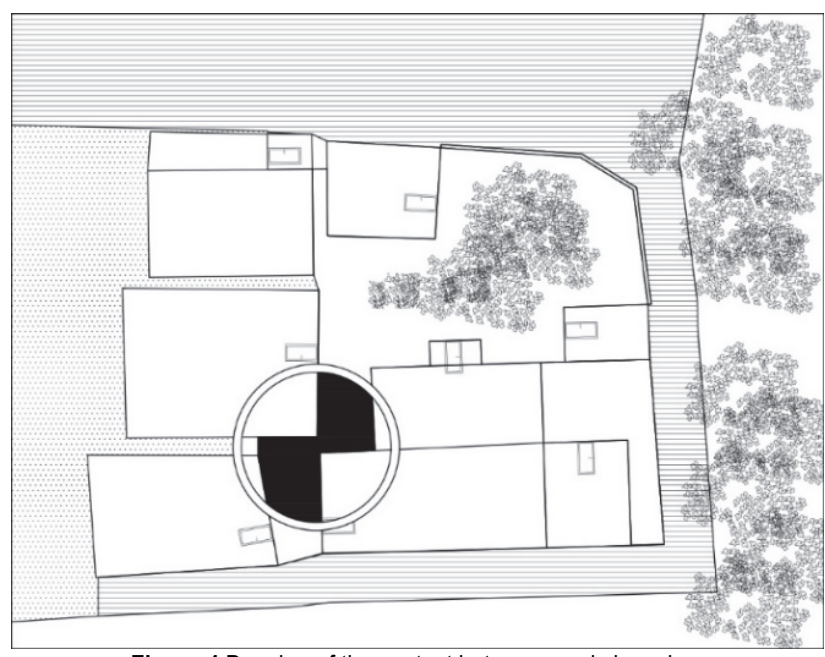

Figure 4 Drawing of the contact between yards in a slum

In compact slums, a certain porosity appears, yet not in the form of alleys/sokak (as defined below), but serves to achieve direct communication between courtyard groups of objects that are 'back-to-back' adjoining each other. This indicates the fact that the courtyard group is fenced off and primarily opens towards the street, but that this does not cause a complete closure and alienation among the neighbours (Fig. 4).

Unlike slums, streets in unsanitary settlements have a solid treated surface, most often paved with asphalt. The width of the cross-section of the street is variable and ranges between 2.5 and $3 \mathrm{~m}$. These streets are predominantly pedestrian with very sparse vehicle traffic, and may contain a widening at the end to turn motor vehicles. Usually, the street often takes on an additional function in the housing service in addition to communication. The dead end street is used as an extended courtyard for the residents in its immediate vicinity, and there are cases when the vertical communication, i.e. the steps for the subsequently built floor of the house, are located on the street (Fig. 5). In that context, the treatment and meaning of the street take the form of a semi-private space, i.e. they indicate the fact that life does not happen in seclusion from the street. Due to the lack of courtyard space, the street is becoming a necessary resource for a function in the housing service, so such interventions of overlapping private and public communication in the context of semi-private transitional forms are possible, but not common. Also, if due to the expansion of the house, the courtyard becomes too small for children to play, the street takes over the role of the courtyard, so the children play in front of the fence of their house in the street, i.e. in the immediate vicinity of the house (Fig. 6).

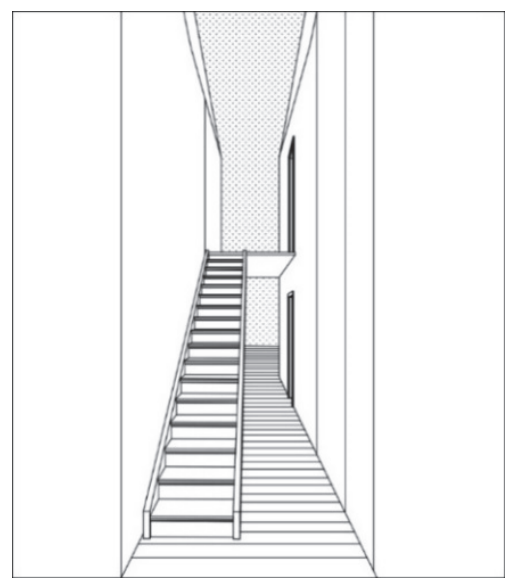

Figure 5 Drawing of the ambience of overlapping private and public communication in an unsanitary settlement

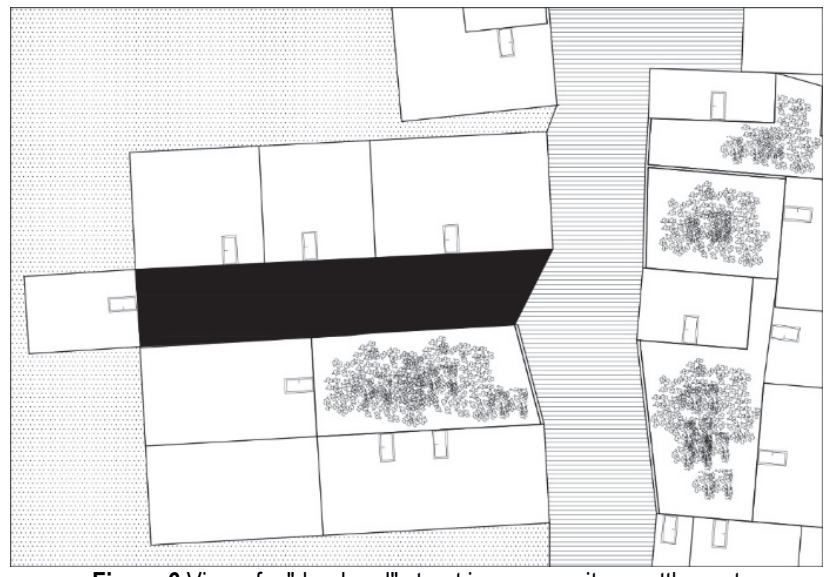

Figure 6 View of a "dead end" street in an unsanitary settlement

In one unsanitary settlement (Rupe settlement Belgrade, Serbia) there is a special, almost hybrid case 
when the street becomes a trade zone and a contact zone with non-Romani population. In that case, the yard receives a new dimension and often behind the gate, which is completely open, open markets (flea markets) are organized during the weekdays, and "stands" are set up in the courtyard. In that context, the layout of the living space is additionally motivated by the preservation of the courtyard (Fig. 7). In case it is necessary to build a courtyard, the covered porch of the house, in addition to the usual role, also takes on this, commercial, one.

In unsanitary settlements, another form of communication was observed in the form of a narrow space between houses, 1.2 - $1.5 \mathrm{~m}$ wide, which can be called an alley/sokak. Sokak (alley) is a Turkish word that usually means a smaller shopping street, and often means a small street - 'alley' - unrelated to the trade. In the context of the research, the term sokak (alley) was chosen to indicate this space/passage since it suggests and emphasizes the intimate character of a street with a narrow cross-section (physical feature) and a retention spaces (social feature). In unsanitary settlements houses are rarely adjoining each other. If a new, separate house is built in the courtyard, it is not adjoined to the existing building, but moved away by $1-2 \mathrm{~m}$. Based on the results of previous research by the author [6], it was determined that this way of construction represents the heritage that was retained when dilapidated houses were replaced by permanent or more durable buildings. Namely, dilapidated houses never adjoin each other, instead, an interspace of $1-1.5(\max 2) \mathrm{m}$ width is always maintained due to possible repairs on the house. When it came to construction with solid materials, in most cases, this space was retained, but it was converted into an alley. The alley in the blocks of unsanitary settlements enables spatial porosity, thus forming introverted settlement connections and 'shortcuts' within the immediate neighbourhood and the entire community. Alley is not just a transition area, but often carries a social connotation of backyard. Compared to streets that are more public, less intimate, having faster daily rhythm, alleys are not only places for circulation, but also places for staying, socializing, relaxing (Fig. 8).
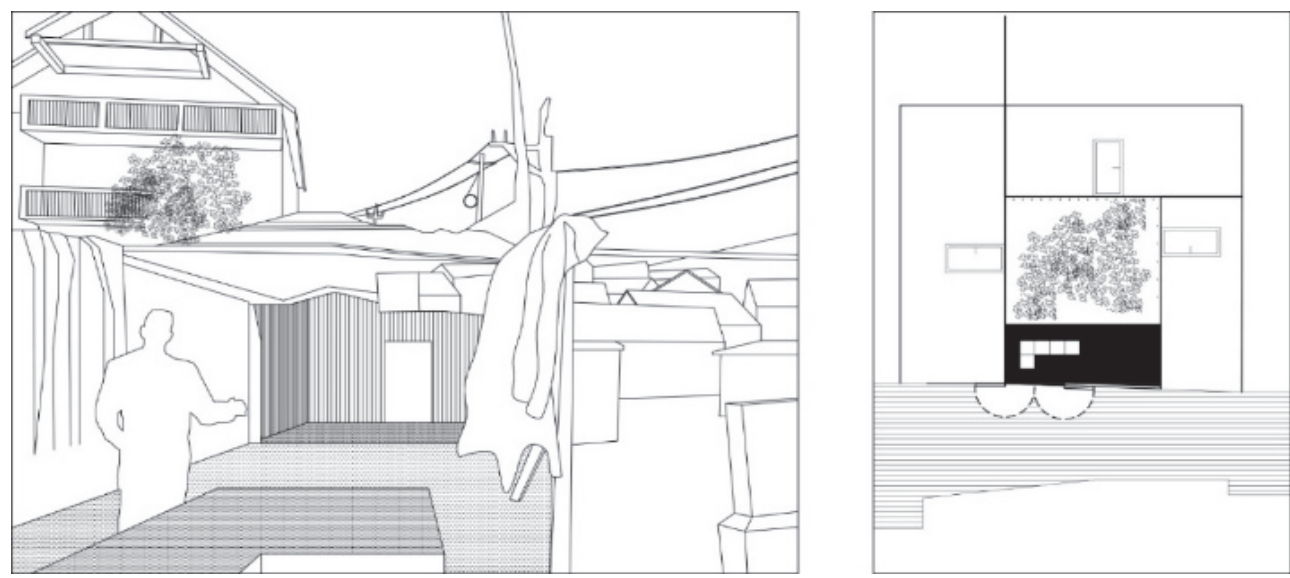

Figure 7 Ambience of the courtyard stand of open market in the Rupe settlement
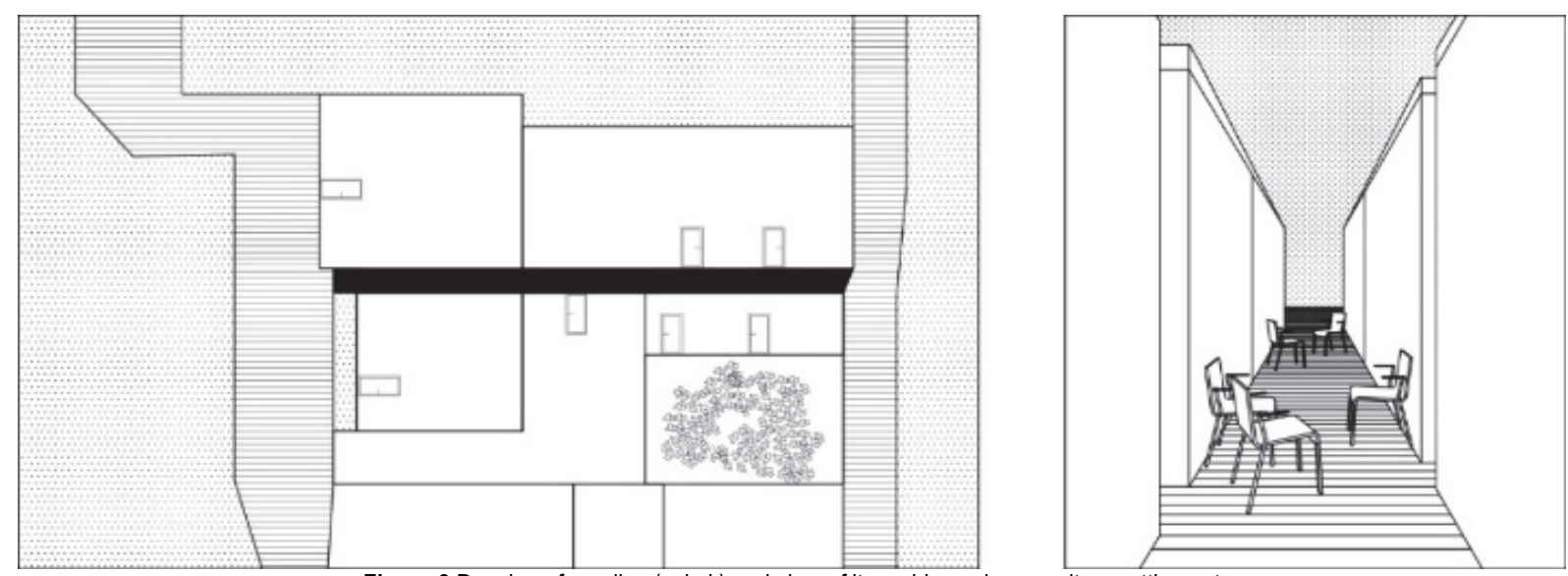

Figure 8 Drawing of an alley (sokak) and view of its ambience in unsanitary settlement

As a conclusion of the research of the current situation, the fact is imposed that the streets in Romani settlements have a complex character with a significantly pronounced degree of integration of users. Streets in slums are areas of communication, connecting elements of courtyard building groups, but they are also spaces that the daily rhythm of residents initiates into gathering spaces. Analysis of the user's trampled tracks in the slums, revealed the fact that the street is bi-functional, i.e. that the central part of the area serves as traffic communication, and that the peripheral parts serve for gathering. This context of gathering and socializing is conditioned by the construction of the settlement lot along the perimeter, so that all the houses are oriented towards the inner courtyard which opens towards the street or the gathering space. The visual and functional indirect connection of the courtyard of each lot with the family connection is undoubtedly product of the collective way of life which strengthens both the functional and cultural 
dimension of the community. This tendency is even more emphasized in unsanitary settlements. Due to the higher building density, and the lack of separate gathering space, the street does not have a divided area, but its entire area is used as if it were a large common yard of the close neighbourhood.

Alley/sokak, as an unexpected form of communication, in addition to being a local transit area, also serves as an area for secondary extended housing activities. At the level of the closer neighbourhood in the way of use, it is recognized as a static branch of the courtyard, and at the community level, as a secondary pedestrian communication that connects and networks the entire settlement (which again serves to strengthen the functional and cultural dimensions of the community). Sokak, therefore, represents a significant spatial and social asset of the community and an important element that should be preserved as a communicative spatial structure in the reconstruction or design of settlements.

\section{DISCUSSION: PROGRAM PRINCIPLES FOR DESIGN OF TRAFFIC AREAS}

Based on the results of the research, the approach to the design and planning of roads in Romani settlements has been highlighted and discussed in several key aspects, as follows.

\subsection{Functional Basics}

It is clear that the Romani settlements, although functioning according to specific rules, cannot survive apart from the rest of the urban settlements within which they are formed, nor function without connecting to the city road network. In this regard, it is generally known that the road network in urban settlements justifies its functionality by fast and reliable transport of people and goods within the impact zone. In order to achieve such functionality and role in the organization of urban settlements, the city road network is divided into primary (with the task of connecting parts of urban territory by means of traffic) and secondary (with the dominant role of servicing locations and facilities directly along the road). The primary city road network is the most important element of the traffic base of a city. On the other hand, the secondary network is completely subordinated to the specific function of access to urban activities and is considered a separate planning and design unit. As a rule, the requirements for the secondary network (access streets) can be met in the following two ways [9]:

- by partial separation of pedestrians and vehicles in motion and at rest with a speed limit (up to $30 \mathrm{~km} / \mathrm{h}$ ) or

- by full integration of motor traffic in motion and at rest with the joint use of areas under conditions acceptable for pedestrians.

This practically defines the following two categories of access roads (Fig. 9):

- level I access street order where it is necessary to apply a certain degree of separation and protection of cyclists and pedestrians in the cross section,

- level II access street with full integration of all types of traffic, with joint use of the entire width of the street, but tailored to pedestrians.
A common feature of the streets in all observed settlements is that, regardless of the type of settlement, the streets practically belong to the secondary network which consists of a network of internal, access streets to courtyards, residential and auxiliary facilities, as well as other useful areas.

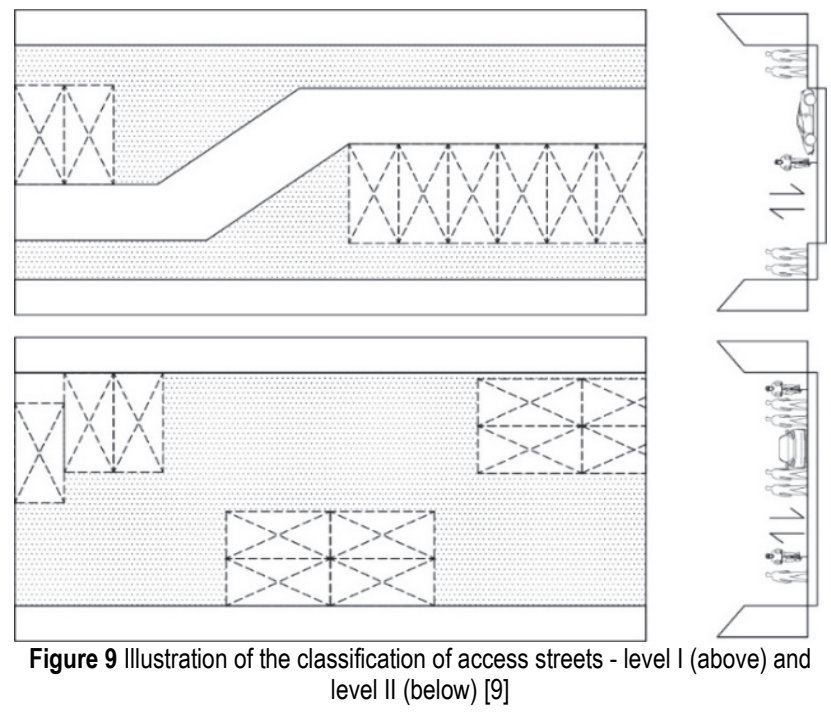

\subsection{Urban Planning and Design or Planning and Design of Traffic Areas}

The arrangement of traffic areas in Romani settlements, as well as in other categories of local roads, is a consequence of urban development, regardless of the level of development achieved or the level of development sought. In local roads, where access to the site and its use are the dominant function, the leading process is necessarily urban planning and design. This implies the required level of project research as a physical verification of planning commitments. This would mean that the planning and design of traffic areas is in fact an accompanying process within the leading process of urban planning. This is especially emphasized in the potential reconstruction of existing traffic areas when there is no major change in the type and/or intensity of urban contents, as in the case of Romani settlements. In this case, there is no possibility of applying spatial models of the local network in its original form, but it is necessary to make a compromise between the required functional characteristics and spatial possibilities, as well as the specific way of life and functioning of the Romani community.

As the research established, the network of traffic areas in the Romani settlement, in any case, represents an organized set of traffic infrastructure with dominant functions of access to certain content and gatherings, as well as vehicle parking on a smaller scale. Unlike the classic forms of local road network, where one of the main goals is to calm traffic and eliminate traffic flows through a certain area, the streets in Romani settlements by their very nature and the environment in which they are located do not have such a problem. Special structural interventions in the cross section and at intersections, and traffic regulation measures are losing their significance because the way of using the space between buildings in 
the settlement practically forces calm movement of vehicles and enables domination of 'weaker' userspedestrians, cyclists, animal-drawn vehicles.

Utilities, as one of the dimensioning parameters, are less dominant on the streets in Romani settlements. However, due to the need and ultimately, due to obligation of society and government to ensure the health and safety of any community, to some extent, through appropriate regulation and provision of clear profiles, it is at least necessary to provide access to essential utility vehicles, such as fire department trucks, vehicles for maintenance and repairs of sewerage and water supply network, ambulance, police. The access of other types of communal vehicles is not necessary and services may be rendered from the neighbouring streets of city road network (municipal waste vehicles, vehicles for maintenance and repair of electric network, etc.) Therefore, as with the level II access street, on the main road in the settlement, one should strive for traffic calming and integration of users in relation to pedestrian movements. At a lower level, the basic goal is to maintain the spirit and intimacy of the community.

\subsection{Nonexistence of Regulatory Basis}

However, for more precise definition of stated principles, the existing regulations (laws and by-laws, technical regulations, technical standards) do not specifically treat the street network for social housing. For example, for the city of Belgrade, General Plan [10] contains data only for the street network in which parking is additionally provided in the main and side streets and inside the courtyards. The dimensions of the streets for social housing, envisaged by the General Plan, are: the carriageway width of the main street is $10-15 \mathrm{~m}$, the carriageway width of the secondary street is $6-9 \mathrm{~m}$ and the width of the pedestrian path is $1.5-4.5 \mathrm{~m}$.

The omission of the existing regulation (rules and standards) is also interesting when it comes to solving the city road infrastructure in general. The regulatory gap in the region, which is the subject of research, is most often tried to overcome by using a set of six books (non-binding) of technical instructions for planning and design of traffic infrastructure in cities [11] which have been used for several years in the practice of engineers engaged in planning and design of city roads. In addition, international experiences are used, emphasizing that such ways of organizing social housing areas and associated traffic areas are generally not addressed through regulations, but only general recommendations are given, primarily in the purposefully dedicated planning documentation for individual units when necessary.

Vuksanović-Macura and Macura [8], in the case of planning the improvement of existing Romani settlements, recommend that the existing street network should be included as a starting point, and that the regulation of street profile can be changed in case that there is need to build an infrastructure, by regulating the street elevation in accordance with the surrounding courtyards and houses or buildings, as well as to provide extensions for passing bays. Also, the cross section should provide the possibility to build or reconstruct appropriate types of utility infrastructure. In some streets, all infrastructure will be built, while in others it will be possible to build only those that require less space.

Animal-drawn vehicles and tractors which are found in some Romani settlements, especially on the outskirts, require that appropriate profiles and curves radiuses are provided when designing the street network. Parking of various types of vehicles should be solved either through groups of a small number of parking spaces, or longitudinally on streets that have sufficient width, or on lots. Due to poverty, the real problem of parking does not exist at the moment, but it will occur in the future [8].

\subsection{Program Principles}

In relation to the previously analysed and stated, as a synthesis of knowledge from the field, practice and recommendations from the existing design basis, it is possible to determine the basic program principles for planning and design of traffic areas in Romani settlements (Tab. 1).

By observing the street as a higher functional level, with the character of public and semi-public area, it is possible to make a selection of its character and in accordance with that to perform dimensioning as provided by the planning documentation for social housing settlements. If during the design or reconstruction of the settlement it is not possible to form a courtyard buildings group due to population density, the character of the street should be such as to compensate for certain courtyard functions (similar to an integrated street) and parameters for integrated streets can be applied accordingly.

It is practically possible to organize the entire area in free arrangement, without distinguished geometric rules, but still with respect to certain requirements for the pass ability of certain types of vehicles (dimensions of the clear profile and minimum radii). Only a certain, smaller part of the street area can be used for parking, and other parts for other functions (gathering, children's play, trade, greenery, etc.).

In order to improve hygienic conditions and protect property, it is necessary to ensure efficient drainage of water to the lowest points where the gullies are located, as well as to apply curbs of lower heights towards courtyards that will provide the minimum necessary protection and will not be a major obstacle to communication and unimpeded entry into lots of the courtyard building groups. As already pointed out in the analysis of the current situation, the main communications are usually ending in a dead end street and have a turning point, so that this form should be kept for the future. Thereby, it is sufficient to use more modest turning points with dimensions that allow turning with additional manoeuvring for passenger and other vehicles up to $8 \mathrm{~m}$ long (utility vehicles).

In the case of alleys (sokak), i.e. passages, it is necessary to emphasize that, although certain planning documents determine the width of pedestrian paths in settlements intended for social housing in the range of 1.5 - $4.5 \mathrm{~m}$, it should be taken into account that the cross section of alley should maintain the established intimacy, that affected its development as retention area, in the existing condition. Therefore, it is recommended that width of cross section should not exceed $2 \mathrm{~m}$. 
Table 1 Program principles for traffic areas in Romani settlements

\begin{tabular}{|c|c|c|}
\hline \multirow{2}{*}{ Relations } & \multicolumn{2}{|c|}{ Features of spatial traffic structures } \\
\hline & street & alley (sokak)/passage \\
\hline Users & - community/community and close neighbourhood & - community/close neighbourhood \\
\hline $\begin{array}{l}\text { Degree of privacy according to } \\
\text { the right of use }\end{array}$ & - public and semi-public & - semi-public \\
\hline $\begin{array}{l}\text { Support in preserving cultural } \\
\text { identity }\end{array}$ & $\begin{array}{l}\text { - strengthening within the group connection of the } \\
\text { community and enabling the continuation of common } \\
\text { patterns of social practices }\end{array}$ & $\begin{array}{l}\text { - strengthening within the group connection of the } \\
\text { community and closer neighbourhood, and enabling } \\
\text { the continuation of common patterns of social } \\
\text { practices }\end{array}$ \\
\hline Way of use & $\begin{array}{l}\text { - communication area } \\
\text { - gathering point of closer neighbourhood }\end{array}$ & $\begin{array}{l}\text { - } \text { pedestrian passage } \\
\text { - } \text { retention area } \\
\text { - } \text { building the secondary pedestrian network system } \\
\text { through the settlement }\end{array}$ \\
\hline $\begin{array}{l}\text { Recommendations for } \\
\text { dimensioning }\end{array}$ & $\begin{array}{l}\text { - } \text { gathering point } \\
\text { - integration of all users (vehicles, pedestrians, cyclists, } \\
\text { animal-drawn vehicles) at one surface } \\
\text { - } \text { width of cross section } 5 \text { - } 7 \mathrm{~m} \\
\text { - } \text { widening for passing bay (including the gathering } \\
\text { function) } \\
\text { - obligatory turning point at the dead end of the street } \\
\text { - parking - dominant in the courtyards of the buildings, } \\
\text { possible longitudinally with an extension of an } \\
\text { additional } 2 \mathrm{~m} \text { if the width of the transverse profile is } 5 \\
\text { m } \\
\text { utility installations }\end{array}$ & $\begin{array}{l}\text { - it is necessary to maintain the intimate character of the } \\
\text { space with a cross section width of } 1.5-2 \mathrm{~m} \\
\text { - enable retention area }\end{array}$ \\
\hline $\begin{array}{l}\text { Recommendation for surface } \\
\text { finishing }\end{array}$ & $\begin{array}{l}\text { - solid surface made of asphalt or concrete/modular } \\
\text { concrete elements }\end{array}$ & $\begin{array}{l}\text { - solid surface made of concrete/modular concrete } \\
\text { elements }\end{array}$ \\
\hline
\end{tabular}

\section{CONCLUSION}

Based on classification and systematization of data obtained on methodological basis of overlapping the spatial and social level in Romani settlements, at least three key places of justified knowledge basis are identified that relativize the concept of street/road design in relation to the usual design approach.

Namely, the usual spatial use of streets as traffic areas in the cultural system of the Romani community, which is dominated by the collective way of life, necessarily integrates certain sequences of interpretation of the street as open spaces intended for gathering and entertainment. This means that in the design sense, it is not enough to simply apply spatial models in their original form, but it is necessary to apply other parameters of spatial design in the form of creative compromises between required functional characteristics, spatial possibilities and specific way of life and functioning of Romani community. This necessarily requires to create special design principles that would be transferred and used in planning and design documentation, and that the planning, design and construction of the local street network, in relation to 'urban' development and demand for traffic services, is resolved consequently.

Also, the interpretation and reading of ethnological and sociological patterns in the use of streets in Romani settlements as public areas for people stay, places to strengthen group connections, housing expansion, places of trade, contact zones with non-Romani population, undoubtedly suggest that the principle of traffic integration starting from the most sensitive type - pedestrians (similar to level II access street) should be predominantly applied, while the unification of dynamic characteristics of different traffic modes would occur as a consequence of using free space without the need for additional structural restrictions.
Accepting alleys as specific spatial entities, as shown by the research, should be included in all revitalization or design plans according to proposed model of pedestrian network, since the alleys have semantic value in maintaining system of common determinants of the group and strengthening of collective way of life which provides cohesion of the entire settlement.

Thus, by establishing the relationship between the specific patterns of behaviour when using certain spatial forms, information was obtained that has the ability to include the traffic network as a very complementary support to other functions (housing) and make it one of the carriers in creating adequate housing for the Romani community. In other words, such a procedure would achieve an additional effect the street network would, in addition to its basic function, have the potential to meet special spatial requirements related to enabling the development of cultural characteristics of users that primarily affect the strengthening of group connections, which Berescu insists on [12], with the final goal to provide adequate living conditions acceptable to Romani population, which is in the sphere of social superstructure and social consciousness, a desirable link in the interculturalization of social life.

What follows as a continuation of this basic research, which resulted with the main knowledge about the impact of Roma lifestyle on their daily communication and use of certain areas within settlements, is to apply the defined program principles as a pilot study on a selected representative sample, basically for one of the identified and analyzed settlements within the study area. Such research would properly show the actual level of acceptance of the proposed concepts that have generally received a positive attitude in a verbal sense through conversations with the residents of these settlements and their elders. The pilot project would also provide a broad basis for improving the regulatory, planning and 
administrative framework (mostly guidelines for arrangement, rather than rulebooks or decrees) by which state and city authorities could direct actions to improve life in Roma communities as opposed to a rigid way of organizing social housing that is not appropriate for Roma culture and lifestyle.

Also, in recent decades, the Romani have sought a way to articulate and define national identity in the way that most modern nations have done. Trying to weave elements into the structure of national identity that will best represent the collective spirit of the nation, the Romani intellectuals referred to traditional determinants, but also to some new ones, which have not been paid attention to in discussions so far. In that sense, the solutions we propose completely have space to be accepted at several levels. Certainly, the most important fact is the strong potential to accept proposed principles by the Roma community (to which we have received their positive opinion during field research) as long as their understanding of the concept of community is respected.

\section{REFERENCES}

[1] Gypsies in Europe, Recommendation No. 1203. (1993). Council of Europe Parliamentary Assembly. Retrieved from: http://assembly.coe.int/nw/xml/XRef/Xref-XML2HTMLEN.asp?fileid $=15237 \&$ lang $=$ en

[2] Novak, J. (2004). The Roma Community and International Institutions: Only Relative Success in the Protection of Human and Minority Rights. Migration and Ethnical Topics/Migracijskeietničketeme, 20(4), 403-432. Retrieved from: https://hrcak.srce.hr/7062

[3] Slaev, A. (2007). Bulgarian Policies towards the Roma Housing Problem and Roma Squatter Settlements, European Journal of Housing Policy, 7(1), 63-84. https://doi.org/10.1080/14616710601134753

[4] Molinuevo, D., Koomen, M., \& Fóti, K. (2012). Living Conditions of the Roma: Substandard Housing and Health, EuropeanFoundation for the Improvement of Living and Working Conditions, Dublin. Availableonline: https://www.eurofound.europa.eu/sites/default/files/ef_publ ication/field_ef_document/ef1202en.pdf

[5] Vuksanović-Macura, Z. (2012). The mapping and enumeration of informal Roma settlements in Serbia.Environment and Urbanization, 24(2), 685-705. https://doi.org/10.1177/0956247812451809

[6] Grbić, M. (2015). Improvement of Spatial Organization of Housing in Romani Settlements in Belgrade under the Influence of the Romanipen Principles. Ph.D. Thesis. University of Belgrade, Faculty of Architecture, Belgrade.

[7] Ozaki, R. (2002). Housing as a Reflection of Culture: Privatized Living and Privacy in England and Japan. Housing Studies, 17(2), 209-227. https://doi.org/10.1080/02673030220123199

[8] Vuksanović-Macura, Z. \& Macura, V. (2007). Romani Settlements and Housing in South-East Europe: Review of the Situation and Progress in Serbia. Association for the Improvement of Romani Settlements, Serbian Institute for Architecture and Urban Planning, Belgrade.

[9] Maletin, M. (2019). Planning and Design of Traffic Infrastructure in Cities. III edition. Orion art, Belgrade.

[10] Urban Planning Institute of Belgrade. (2003). General Plan of Belgrade until 2021. The Official Gazette of the City of Belgrade, No. 27/03.

[11] Maletin, M., Anđus, V., \& Katanić, J. (2010). Technical Instructions for Planning and Design of the Urban Road Network (PGS-M/06); Technical Instructions for Designing
Sections of Primary Urban Road Network (PGS-PM/07); Technical Instructions for Design of Intersections (PGSPR/07); Technical Instructions for Design of Gradeseparated Intersections (PGS-DR/08); Technical Instructions for Designing the Local Urban Road Network (PGS-LM/08); Technical Instructions for Car Park Design (PGS-P/08). Građevinski centar, Belgrade.

[12] Berescu, C. (2011). The rise of the new European Roma ghettos: a brief account of some empirical studies. Urban Research \& Practice., 4(3), 344-352. https://doi.org/10.1080/17535069.2011.616750

\section{Contact information:}

Milena GRBIĆ, PhD., Grad. Arch. Eng., Assistant Professor (Corresponding author)

University of Novi Sad, Faculty of Civil Engineering,

2a Kozaračka Str., Subotica, Serbia

E-mail: mgrbic@gf.uns.ac.rs

Igor JOKANOVIĆ, PhD., Grad. Civil. Eng., Associate Professor University of Novi Sad, Faculty of Civil Engineering,

2a Kozaračka Str., Subotica, Serbia

E-mail: jokanovici@gf.uns.ac.rs

Viktorija ALADŽıĆ, PhD., Grad. Arch. Eng., Associate Professor University of Novi Sad, Faculty of Civil Engineering 2a Kozaračka Str., Subotica, Serbia

E-mail: viktorija@gf.uns.ac.rs

Olivera DULIĆ, PhD., Grad. Arch. Eng., Teaching Assistant University of Novi Sad, Faculty of Civil Engineering 2a Kozaračka Str., Subotica, Serbia

E-mail: olivera@gf.uns.ac.rs 